Ref

NBSIR 79-1605

Al1, $104 \quad 514085$

\title{
A THEORETICAL STUDY OF UNBALANCED GROUND EFFECTS ON RECEIING DIPOLES
}

M. T. Ma

Electromagnetic Fields Division National Engineering Laboratory National Bureau of Standards Boulder, Colorado 80303

May 1979 



\section{NBSIR 79-1605}

\section{A THEORETCAL STUDY OF UNBALANCED GROUND EFFECTS ON RECEIVING DIPOLES}

M. T. Ma

Electromagnetic Fields Division

National Engineering Laboratory

National Bureau of Standards

Boulder, Colorado 80303

May 1979

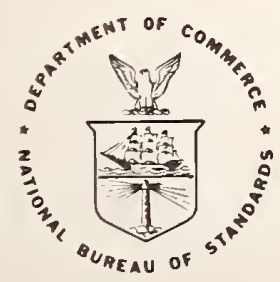

U.S. DEPARTMENT OF COMMERCE, Juanita M. Kreps, Secretary Sidney Harman, Under Secretary Jordan J. Baruch, Assistant Secretary for Science and Technology

NATIONAL BUREAU OF STANDARDS, Ernest Ambler, Director 


\section{CONTENTS}

.1. INTRODUCTION

2. CHANGES IN FIELD STRENGTH CAUSED BY PLANE IMPERFECT GROUND

3. GROUND EFFECTS DUE TO POSITIONAL IMBALANCE OF THE RECEIVING POLE

4. VARIOUS CAPACITANCES BETWEEN THE DIPOLE AND GROUND/TRANSMISSION LINE $\ldots \ldots \ldots$

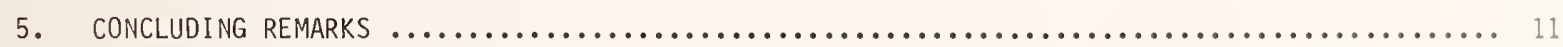

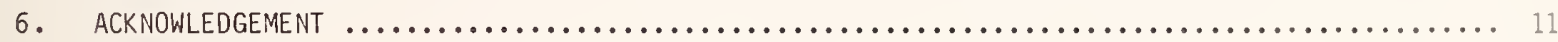

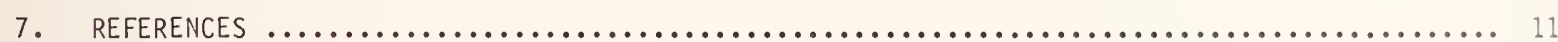





\title{
A THEORETICAL STUDY OF UNBALANCED GROUND EFFECTS
}

ON RECEIVING DIPOLES

\author{
M. T. Ma
}

Balanced ground effects on the performance of some antenna systems are relatively well known and can be taken into account by the design engineer. Unbalanced ground effects on a measuring system are, however, more complicated and make a thorough understanding difficult. In this report, specific ground effects on the calibration of a dipole antenna with an arbitrary inclination angle with respect to the ground are analyzed by means of a theoretical model. Numerical results representing this undesired effect are also included.

Key Words: Dipole antenna; ground effect; unbalanced system.

\section{INTRODUCTION}

Characterization of an electromagnetic environment at a given point in space can best be accomplished by systematic measurements with a broadband antenna. One of the antenna systems may consist of three orthogonal short dipoles. Another may be one with three orthogonat 10op antennas. To measure the incoming field with different polarizations, the mutualiy orthogonal antennas are usualiy arranged in such a manner that they are neither parallel nor perpendicular to the ground plane. Because of this positional inclination of the measuring dipole itself with respect to the ground, the two halves of the dipole will experience a different ground effect, giving different results at different measurement heights. This, in turn, causes difficulty in calibrating the antenna.

In the actual measurement program, we used a known vertical antenna installed above a ground system to generate the transmitting field, and employed both the orthogonal dipoles and loops for measurement. The frequency range of interest is about $10 \mathrm{kHz}$ to $100 \mathrm{MHz}$. Spot measurement results showed a difference of as large as three decibels in received signal levels for the dipole, when the measurement height was changed from $1 \mathrm{~m}$ to $2 \mathrm{~m}$ above the ground. No significant changes in measurenent results were observed, however, by the loop antenna for the lower end of frequency range. This discrepency in actual measurement results by the inclined dipole prompted the study contained in this report.

Another mechanism that may cause different signal levels at different measurement heights is a change in the transmitted field strength by the plane imperfect ground even though a ground systen has been provided for the transmitting antenna.

Theoretical models for each of the above mechanisms and some numerical results are presented here.

\section{CHANGES IN FIELD STRENGTH CAUSED BY PLANE IMPERFECT GROUND}

Because the ground plane on which a transmitting antenna is erected may not be perfect, the field strength radiation pattern in the vertical plane near the ground surface is quite different from that transmitted by an antenna over a perfect ground. The space-wave radiation pattern of a base-fed vertical linear antenna over a flat earth, as shown in figure 1, may be mathematically expressed as [1]

$$
E_{\theta}=\frac{C}{\sin \theta}\left[A+j B+R_{v}(A-j B)\right], v / m,
$$


where

$$
\begin{aligned}
& A=\cos (k h \cos \theta)-\cos k h, \\
& B=\sin (k h \cos \theta)-\cos \theta \sin k h, \\
& C=a \operatorname{constant}, \\
& R_{V}=\frac{\cos \theta-\left(k / k^{\prime}\right)\left[1-\left(\sin \theta k / k^{\prime}\right)^{2}\right]^{1 / 2}}{k^{1 / 2}}, \\
& k^{\prime}=k\left[\varepsilon_{r}-j 18 \sigma\left(10^{3}\right) / f_{M H z}\right]^{1 / 2}, \\
& f_{M H z}=\text { the operating frequency in MHz, } \\
& k=2 \pi / \lambda, \\
& \lambda=\text { the operating free space wavelength in } m, \\
& \varepsilon_{r}=\text { the dielectric constant of the earth, } \\
& \sigma=\text { the earth conductivity in mho/m, } \\
& h=\text { the antenna height in m, and } \\
& \theta=\text { the zenith angle measured from the } z \text { axis in degrees. }
\end{aligned}
$$

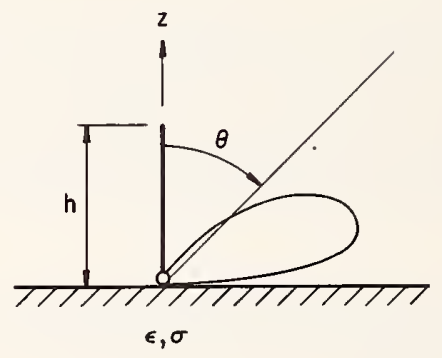

Figure 1. A base-fed vertical monopole.

Note that in eq (1) we have assumed a simple sinusoidal distribution for the antenna current. Note also that at the ground surface $\left(\theta=90^{\circ}\right)$, we have $B=0, R_{V}=-1$, and $E_{\theta}=0$. A typical space-wave pattern over an imperfect earth is also shown in figure 1. 
Now, suppose we have a dipole receiving antenna with the same polarization installed at a distance from the transmitting antenna as depicted in figure 2. Naturally, when the receiving antenna terminal

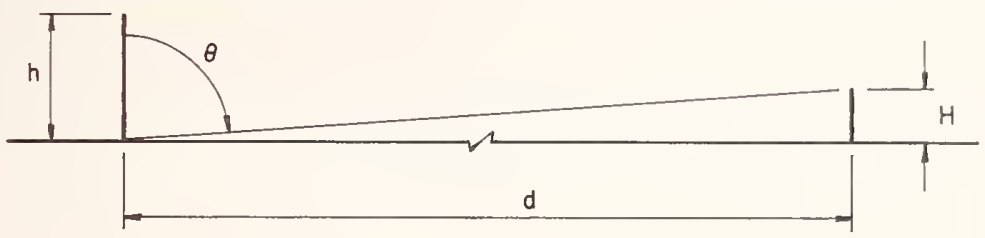

Figure 2. A pair of transmsitting and receiving antennas.

is right at the earth surface $\left(H=0\right.$ and $\left.\theta=90^{\circ}\right)$, the measurement reading should be zero in view of the reason given above, assuming no surface-wave field exists at the measuring site. On the other hand, when $H$ is finite and small, the angle at which the receiving antenna is used for measurement may be approximated by:

$$
\theta=90^{\circ}-\tan ^{-1}(\mathrm{H} / \mathrm{d}) \stackrel{\simeq}{=} 90^{\circ}\left(1-\frac{2 \mathrm{x}}{\pi}\right) \text { degrees, }
$$

where $H$ is the height in meters of the receiving antenna, $d$ is the distance in meters between the transmitting and receiving antennas, and $x=H / d<<1$.

Under the above condition, $\sin \theta \cong 1, \cos \theta \cong \sin (H / d) \cong x$. In addition, if $k h=\pi / 2(a$ quarter-wave monopole for the transmitting antenna), we obtain

$$
A \cong 1 \text { and } B \cong\left(\frac{\pi}{2}-1\right) \cos \theta=\left(\frac{\pi}{2}-1\right) x \text {. }
$$

The field strength at the angle given in eq (2) may be calculated in accordance with eq (1). For example, if the earth is relatively poor (e.g., $\varepsilon_{r}=4$ and $\sigma=0.001 \mathrm{mho} / \mathrm{m}$ ) and $\mathrm{f}_{\mathrm{MHz}}=30$, we have

$$
\begin{aligned}
& k^{\prime} / k=(4-j 0.6)^{1 / 2}, \\
& \operatorname{Arg}\left(k^{\prime} k\right) \cong 0, \\
& \left(k / k^{\prime}\right)\left[1-\left(\sin \theta k / k^{\prime}\right)^{2}\right]^{1 / 2}=0.432+j 0.022 \equiv y, \\
& R_{v}=\frac{x-y}{x+y},
\end{aligned}
$$

and

$$
\begin{aligned}
E_{\theta}(H) & =C\left[\left(1+R_{v}\right) A+j\left(1-R_{v}\right) B\right] \\
& =c(2+j 1.142 y) x /(x+y) \quad v / m .
\end{aligned}
$$

When the height of the receiving antenna is raised to $2 \mathrm{H}$, a similar analysis follows. provided that the parameter $x$ in eq (3) is replaced by $2 x$, where $2 x=2 H / d<<1$. Then the field strength measured ay the receiving antenna should read: 


$$
E_{\theta}(2 H)=c(2+j 1.142 y) 2 x /(2 x+y), \quad v / m .
$$

Since $x<<$, we obtain

$$
E_{\theta}(2 H) / E_{\theta}(H)=2 \sim 6 d B .
$$

On the other hand, when the earth conductivity is very good, such as $\varepsilon_{r}=80$ and $\sigma=5 \mathrm{mho} / \mathrm{m}$, we then have, for the same frequency of $30 \mathrm{MHz}$,

$$
\begin{aligned}
& k^{\prime} / k=(80-j 3000)^{1 / 2}, \\
& \operatorname{Arg}\left(k^{\prime} / k\right) \cong-450, \\
& \left.\left(k / k^{\prime}\right)\left[1-\sin \theta k / k^{\prime}\right)^{2}\right]^{1 / 2} \cong 0.013(1+j) \equiv(1+j) y, \\
& R_{v}=\frac{x-y-j y}{x+y+j y}=-1+x y^{-1}-j x y^{-1}, \\
& E_{\theta}(H)=c\left[y^{-1}+j\left(\pi-2-y^{-1}\right)\right] x, v / m .
\end{aligned}
$$

When the antenna height is replaced by $2 \mathrm{H}$, we again obtain the same result as that given in eq (5). This implies that the field strength measured by a receiving antenna at a height of $2 \mathrm{H}$ meters above an imperfect earth ( $\sigma$ is finite) is approximately 6 decibels more than that measured by the same antenna at one-half of the previous height, when the distance to the transmitter is very much greater than $H$. This difference in measurement results is solely due to changes in the transmitted field strength by the imperfect earth.

When a perfect ground is available, such as the case of installing a very good ground screen on the earth surface, we have $\sigma \rightarrow \infty, R_{V} \rightarrow+1$, and $E_{\theta}(H) \cong 2 C \cos (k h x)$, for $k h=\pi / 2$. Innder this ideal condition,

$$
E_{\theta}(2 H) \cong 2 C \cos (2 k h x) \cong E_{\theta}(H), x<<1,
$$

which implies that the measurement results at two different heights should remain essentially the same.

\section{GROUND EFFECTS DUE TO POSITIONAL IMBALANCE OF THE RECEIVING DIPOLE}

When a dipole receiving antenna is not oriented parallel to the ground surface, such as that shown in figure 3, different ground effects on the lower and upper halves of the dipole will occur, yielding an unbalanced system. We use a capacitance model for the analysis. The capacitances between the lower part of the dipole and the ground/transmission line are different from the corresponding ones between the upper part of the dipole and the ground/transmission line. The unequal ground effects will result in different measurement data at different measurement heights, even though the transmitted field strengths at these heights have the same level (such as those near a perfect ground), which in turn will cause some difficulty in calibrating the receiving antenna. 


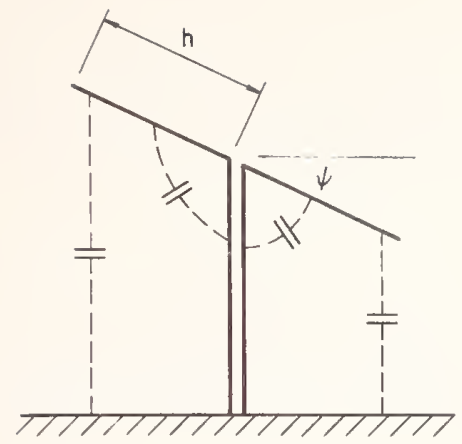

Figure 3. An unbalanced dipole antenna above a perfect ground with vertical connecting transmission line.

The severity of this problem of positional imbalance may be analyzed with the preliminary model network as shown in figure 4. Notations in figure 4 are explained as follows:

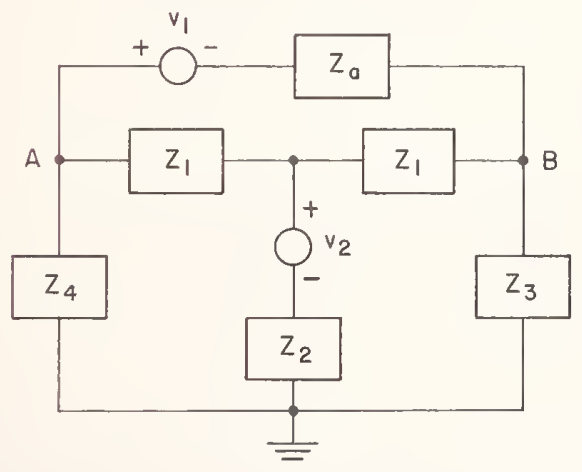

Figure 4. A model network representing the dipole antenna given in figure 3.

$$
\begin{aligned}
z_{a} & =\text { input impedance of the dipole antenna [2] } \\
& =R_{a}-j x_{a}, \text { ohms, }
\end{aligned}
$$

where

$$
\begin{aligned}
& R_{a}=80 \pi^{2}(h / \lambda)^{2}, \\
& x_{a}=120[\ln (h / a)-1] \cot \mathrm{kh}, \\
& h=\text { half length of the dipole in } m,
\end{aligned}
$$


$a$ = radius of the dipole in $\mathrm{m}$;

$v_{1}=$ voltage induced at the dipole terminal by an incoming field

$=E_{\theta} h_{e} \sin \psi$, volts,

where

$E_{\theta}=$ incoming field strength in $v / m$,

and

$h_{e}=$ effective length of the dipole

$\cong h$ for a very short dipole $(h<0.1 \lambda)$;

$Z_{1}=$ an $R C$ divider network of the differential amplifier connected to the dipole

$=R_{1} /\left(1+j \omega R_{1} C_{1}\right) \cong-j\left(1 / \omega C_{1}\right)$ ohms,

where

$R_{1}=3\left(10^{6}\right)$ ohms and $C_{1}=50 \mathrm{pf}$, for the frequency range between $10 \mathrm{kHz}$ and $30 \mathrm{MHz}$;

$Z_{2}=$ impedance per unit length of the transmission line

$=R_{2} /\left(1+j \omega R_{2} C_{2}\right)$ ohms $/ m$,

where

$R_{2}=8,000$ ohms $/ \mathrm{ft}=26,250$ ohms $/ \mathrm{m}$ and $\mathrm{C}_{2}=5 \mathrm{pf} / \mathrm{m} ;$

$v_{2}=$ voltage induced at the terminal of the transmission line by the same incoming field

$\cong \mathrm{E}_{\theta} \mathrm{H} / 2$, volts,

where $\mathrm{H}$ is the length of the transmission line in meters, which is also the measurement height;

$Z_{3}=$ impedance between the lower half of the dipole and the ground, consisting of the self-capacitance of the half dipole wire, the mutual capacitance between the lower half dipole and its ground image, and the capacitance between the same half dipole and the transmission line

$=-j\left(1 / \omega C_{3}\right), \quad$ ohris,

with $C_{3}$ representing the total capacitance in farad;

and

$Z_{4}=$ impedance between the upper half dipole and the ground, consisting of three similar capacitances

$=-j\left(1 / \omega C_{4}\right)$, ohms.

Note that it is not easy to determine the values for $C_{3}$ and $C_{4}$ with a reasonable accuracy, although we know that $\mathrm{C}_{3}>\mathrm{C}_{4}$.

Solving for the three loop currents in figure 4 , we can express the voltage drop between points $A$ and $B$ to represent the actual measurement reading: 


$$
v_{A B}=v_{1} z_{1}\left(z_{1} z_{3}+z_{1} z_{4}+2 z_{2} z_{3}+2 z_{2} z_{4}+2 z_{3} z_{4}\right) / \Delta+v_{2} z_{1} z_{a}\left(z_{4}-z_{3}\right) / \Delta
$$

where

$$
\begin{aligned}
\Delta= & z_{a}\left(z_{1}^{2}+2 z_{1} z_{2}+z_{1} z_{3}+z_{1} z_{4}+z_{2} z_{3}+z_{2} z_{4}+z_{3} z_{4}\right) \\
& +z_{1}\left(z_{1} z_{3}+z_{1} z_{4}+2 z_{2} z_{3}+2 z_{2} z_{4}+2 z_{3} z_{4}\right) .
\end{aligned}
$$

When the measuring antenna is a balanced system such as a horizontal dipole, we have $C_{3}=C_{4}, Z_{3}=Z_{4}$; and, according to eq (15), v $v_{A B}$ does not depend on $v_{2}$. In other words, no matter what the measurement height $H$ is, $v_{2}$ does not play a role. The measurement results at two different heights for the same incoming field with the same polarization should be the same.

For an inclined dipole, $z_{3} \neq z_{4}$. The measurement result of $v_{A B}$ will depend on $v_{2}$ and therefore on $H$. A numerical example is presented below in order to examine quantitatively the dependence of $\mathrm{V}_{A B}$ on $\mathrm{H}$ for a given angle of inclination $\psi$. In addition to the parameters given in eqs (10) and (11), let us also assume $C_{3}=5 \mathrm{pf}$ and $\mathrm{C}_{4}=4 \mathrm{pf}$. Then at $\mathrm{f}=10 \mathrm{kHz}$, we have

$$
\begin{aligned}
& z_{a}=-j 4.76\left(10^{6}\right), \text { assuming } h / a=25 \text { and } h \cong 0.27 \mathrm{~m}(10.5 \mathrm{in}), \\
& z_{1}=-j 0.32\left(10^{6}\right), \\
& z_{2} \cong R_{2}=0.026\left(10^{6}\right) \text { with } H=1 \mathrm{~m}, \\
& z_{3}=-j 3.18\left(10^{6}\right), \\
& z_{4}=-j 3.98\left(10^{6}\right), \\
& v_{1}=0.15 \text { volt, assuming } E_{\theta}=1 \mathrm{v} / \mathrm{m} \text { and } \psi=35.2^{0}, \\
& v_{2}=0.5 \text { volt with } H=1 \mathrm{~m},
\end{aligned}
$$

and, in accordance with eq (15),

$$
v_{A B}(1 m)=0.016814+0.007498=0.024312 \text { volt } .
$$

If $C_{3}$ and $C_{4}$ decrease respectively to $4.55 \mathrm{pf}$ and $3.64 \mathrm{pf}$ when $\mathrm{H}=2 \mathrm{~m}$, we have

$$
\begin{aligned}
& Z_{3}=-j 3.50\left(10^{6}\right), \\
& Z_{4}=-j 4.38\left(10^{6}\right),
\end{aligned}
$$

and

$$
v_{A B}(2 m)=0.016927+0.013833=0.030760 \text { volt } .
$$

Therefore, we obtain

$$
v_{A B}(2 m) / v_{A B}(1 m)=2.04 d B \text {. }
$$

Comparing eqs (16) and (17), we note that, when the measurement height is doubled, the first terms which is the response due to $v_{1}$ does not change much while the second term due to positional imbalance changes substantially. Obviously, the ratio $v_{A B}(2 m) / v_{A B}(1 m)$, depends on $Z_{3}(2 m) / Z_{3}(1 m), Z_{4}(1 m) / Z_{3}(1 m)$, and $Z_{4}(2 m) / Z_{3}(2 m)$. Specific results as functions of these parameters are given in figure 5. 


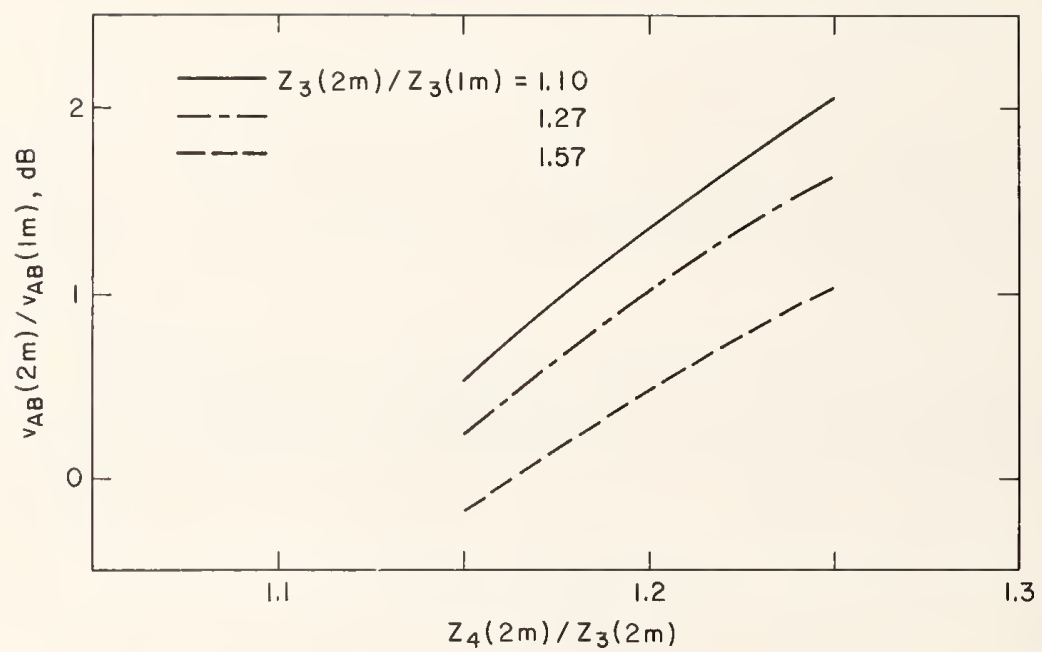

Figure 5. A functional relationship between $v_{A B}(2 m) / v_{A B}(1 m)$ and $Z_{4}(2 m) / Z_{3}(2 m)$ when $\mathrm{Z}_{4}(1 \mathrm{~m})=1.25 \mathrm{Z}_{3}(1 \mathrm{~m})$ and $\mathrm{f}=10 \mathrm{kHz}$.

Note that in the above example $Z_{2}$ is very small relative to $Z_{3}$ and $Z_{4}$, making $Z_{3} Z_{4}$ the dominating term in eq (15). When the transmission line resistance per unit length is increased to $R_{2}$ $=64,000$ ohms/ft achievable by a higher resistance line, we then have $Z_{2} \cong R_{2}=0.21\left(10^{6}\right)$ ohms for $H=1 \mathrm{~m}$, which is still insignificant as compared with $Z_{3}$ and $Z_{4}$. Therefore, the results to be obtained for $v_{A B}(2 m) / v_{A B}(1 m)$ will essentially be the same as those presented in figure 5 . Furthermore, if the operating frequency is increased to $30 \mathrm{MHz}$, making $\omega R_{2} \mathrm{C}_{2}=24.74 \gg>1$, $Z_{2} \cong-j\left(1 / \omega C_{2}\right)=-j 1061$, and at the same time, $Z_{1}=-j 106, Z_{3}=-j 1061, Z_{4}=-j 1362.25$, and $\mathrm{Z}_{\mathrm{a}}=-\mathrm{j} 1574$, we have

$$
v_{A B}(1 m)=0.016937+0.002825=0.019762 \text { volt }
$$

When $H=2 m, Z_{3}(2 m)=1.10 Z_{3}(1 m)=-j 1166$, and $Z_{4}(2 m)=1.25 Z_{3}(2 m)$. Inder this condition,

$$
v_{A B}(2 m)=0.017048+0.005498=0.022546 \text { volt }
$$

or

$$
v_{A B}(2 m) / v_{A B}(1 m)=1.14 d B
$$

which is smaller than the corresponding value of $2.04 \mathrm{~dB}$ obtained previously for $\mathrm{f}=10 \mathrm{kHz}$. 
From the above example and many other numerical results which have not been included here, we may conclude:

(1) that the transmission line impedance $Z_{2}$ itself is not likely to cause any significant change in $V_{A B}$ for different measurement heights, except that the transmission line with higher resistance per unit length may reduce the capacitance between itself and the dipole,

(2) that a higher frequency makes a smaller change in $v_{A B}$ than a lower frequency does for the same structure,

and

(3) that the basic reason for a substantial change in $v_{A B}$ is mainly due to a change in the ratio of $Z_{4} / Z_{3}$ versus measurement height $H$.

In view of this conclusion, a closer study of the possible range for the capacitances shown in figure 3 (therefore, for the ratio of $Z_{4} / Z_{3}$ ) is given in the following section.

\section{VARIOUS CAPACITANCES BETWEEN THE DIPOLE AND GROUND/TRANSMISSION LINE}

For the convenience of presentation, let us designate the self-capacitance of the half-dipole wire by $C_{0}$, the mutual capacitance between the lower half dipole and its ground image by $C_{g}$, and the capacitance between the same half dipole and the transmission line by $C_{t}$ (see fig. 3 ). The total capacitance for the lower half dipole at $H=1 \mathrm{~m}$ may be written as

$$
C_{3}(1 m)=C_{0}+C_{g}+C_{t}
$$

Similarly, the corresponding total capacitance for the upper half dipole is

$$
C_{4}(1 m)=C_{0}+C_{g}^{1}+C_{t}^{\prime}
$$

where

$C_{g}^{\prime}=$ the mutual capacitance between the upper half dipole and its ground image (which should be less than $C_{g}$ ),

and

$C_{t}^{\prime}=$ the capacitance between the upper half dipole and the transmission line (which should be less than $C_{t}$ ).

Because the inclination angle of the dipole with respect to ground is approximately $35.2^{\circ}$ and the ground image capacitance is inversely proportional to the separation, we may express:

$C_{g}^{\prime} / C_{g}=\left(1-0.5 \times 10.5 \times 2.54 \times 0.01 \sin 35.2^{0}\right) /\left(1+0.5 \times 10.5 \times 2.54 \times 0.01 \sin 35.2^{0}\right)=0.857$

or

$$
C_{g}^{\prime}=0.857 C_{g}
$$

In eq (22), we have used 10.5 inches for the length of half dipole.

An approximate relation between $C_{t}$ and $C_{t}^{\prime}$ is, however, not available. Using eqs (20). (21). 


$$
\frac{z_{3}(2 m)}{z_{3}(1 m)}=\frac{c_{0}+c_{g}+c_{t}}{c_{0}+0.480 c_{g}+c_{t}} \text {, }
$$

and

$$
\frac{z_{4}(1 \mathrm{~m})}{z_{3}(1 \mathrm{~m})}=\frac{c_{0}+c_{g}+c_{t}}{c_{0}+0.857 c_{g}+c_{t}^{\prime}} .
$$

Setting values for $Z_{3}(2 m) / Z_{3}(1 m)$ and $Z_{4}(1 m) / Z_{3}(1 m)$, we may solve for $C_{g} / C_{0}$ and $C_{t} / C_{0}$ with an assumed range of values for $C_{t}^{t} / C_{t}$. Numerical results on this are given in table 1. In this table, we have chosen a range of 1.10 to 1.25 for $Z_{3}(2 \mathrm{~m}) / Z_{3}(1 \mathrm{~m})$ and a range of 1.15 to 1.25 for $Z_{4}(1 \mathrm{~m}) / Z_{3}(1 \mathrm{~m})$ such that the values obtained for $C_{g} / C_{0}$ and $C_{t} / C_{0}$ have a reasonable range of 0.3 to 0.9 . Otherwise, either negative values or values greater than unity for $C_{g} / C_{o}$ and $C_{t} / C_{o}$ will result, which are certainly not reasonable.

We also include the results of $v_{A B}(2 m) / v_{A B}(1 m)$ and $v_{A B}(10 m) / v_{A B}(1 m)$ in the table, where the assumptions that $v_{2}(2 \mathrm{~m})=2 v_{2}(1 \mathrm{~m})$ and $v_{2}(10 \mathrm{~m})=10 v_{2}(1 \mathrm{~m})$ have been made. It is clear from this table that in order to keep the change of vaB due to variation in measurement heights to a minimum, we should require that $Z_{3}(2 \mathrm{~m}) / Z_{3}(1 \mathrm{~m})$ be as 1 arge as possible and that $Z_{4}(1 \mathrm{~m}) / Z_{3}(1 \mathrm{~m})$ be as small as possible. To achieve the latter objective, it may be feasible to insert some dielectric material between the upper half dipole and the ground for the purpose of increasing $\mathrm{C}_{4}$ (decreasing $\left.Z_{4}\right)$ to reduce the ratio of $Z_{4}(1 \mathrm{~m}) / Z_{3}(1 \mathrm{~m})$. Any other means of reducing $v_{2}$ such that $v_{2}(n m)<n v_{2}(1 m)$ will also help, by reducing the contribution of the second term in eq (15).

Table 1. Realistic ranges for various capacitances.

\begin{tabular}{|c|c|c|c|}
\hline$Z_{3}(2 \mathrm{~m}) / Z_{3}(1 \mathrm{~m})$ & $Z_{4}(1 \mathrm{~m}) / \mathrm{Z}_{3}(1 \mathrm{~m})$ & $v_{A B}(2 \mathrm{~m}) / v_{A B}(1 \mathrm{~m}), \mathrm{dB}$ & $v_{A B}(10 \mathrm{~m}) / \mathrm{v}_{A B}(1 \mathrm{~m}), \mathrm{dB}$ *⿻ \\
\hline \multirow{3}{*}{1.10} & 1.25 & 2.92 & 13.51 \\
& 1.20 & 2.58 & 12.56 \\
& 1.15 & 2.12 & 11.24 \\
\hline \multirow{3}{*}{1.20} & 1.25 & 2.64 & 12.92 \\
& 1.20 & 2.23 & 11.80 \\
& 1.15 & 1.69 & 10.11 \\
\hline \multirow{2}{*}{1.25} & 1.25 & 2.48 & 12.64 \\
& 1.20 & 2.07 & 9.51 \\
\hline
\end{tabular}

*In the table above, we have used the following ratios, similar to eqs (23) and (24):

$$
\begin{aligned}
& \frac{z_{3}(10 m)}{Z_{3}(1 m)}=\frac{c_{0}+c_{g}+c_{t}}{c_{0}+0.093 c_{g}+c_{t}} \\
& \frac{z_{4}(10 m)}{Z_{3}(1 m)}=\frac{c_{0}+c_{g}+c_{t}}{c_{0}+0.092 c_{g}+c_{t}^{\prime}}
\end{aligned}
$$

A final remark concerning possible use of a transmission line with a higher resistance per unit length is in order. As we noted earlier, a higher value of $Z_{2}$ should not exert much effect on $v_{A B}$. However, when the resistance per unit length of the transmission line is higher, the capacitance between the line and the half-dipole wire may be substantially reduced. In terms of the 
notations used, the parameters $C_{t}$ and $C_{t}^{\prime}$ in eqs (23) and (24) will be smaller, which makes $z_{3}(2 m) / Z_{3}(1 m)$ increase and $Z_{4}(1 m) / Z_{3}(1 m)$ decrease. These changes are in the right direction to cause a lesser variation in $v_{A B}$. As an example, when $Z_{3}(2 m) / Z_{3}(1 m)=1.10$ and $Z_{4}(1 \mathrm{~m}) / Z_{3}(1 \mathrm{~m})=1.25$ corresponding to the result of the first line given in table 1 , where $C_{g} / C_{0}=0.304, C_{t} / C_{0}=0.434$, and $C_{t}^{\prime} / C_{t}=0.30$. If $C_{t} / C_{0}$ is reduced to, say, 0.25 with $C_{g} / C_{0}$ and $C_{t}^{\prime} / C_{t}$ unchanged, we obtain $Z_{3}(2 m) / Z_{3}(1 m)=1.113$ and $Z_{4}(1 \mathrm{~m}) / Z_{3}(1 \mathrm{~m})=1.164$, which are respectively larger and smaller than the values for low-resistance transmission line.

Thus, from the consideration of minimizing the unbalanced ground effect, we should use a transmission line with the highest possible resistance per unit length. However, from the practicality and power supply viewpoints, there is a limitation in this regard. The transmission 7 ine with 210,000 ohms/m (64,000 ohms/ft) used in the above illustrative example is probably the limit we can use in this particular application.

\section{CONCLUDING REMARKS}

In this report, we have examined unbalanced ground effects on the performance of a receiving dipole through a parametric study. Specifically, the voltage drop across the terminal of the receiving antenna was considered under two different situations. In the first, a variation in the transmitted field strength due to an imperfect earth was analyzed while the effect due to positional imbalance of the receiving dipole was neglected. In the second situation, ground effects resulting from tine unbalanced position of the receiving dipole were studied through a theoretical model by assuming no variation in the transmitted field strength. In reality, changes in measurement results with different antenna heights may be a combined consequence of both. More systematic measurements are required to help identify the degree of dependence on each of these causes. If the second cause is identified as the real reason for variations in measurement results, possible means for reducing the unbalanced ground effect on the receiving system being examined were also suggested.

\section{ACKNOULETGMENT}

The author wishes to express his appreciation to $C$. Reeve for his help and consultation throughout this study and to M. Kanda and C.K. S. Miller for reviewing the draft manuscript.

\section{REFERENCES}

[1] Ma, M. T., Theory and Application of Antenna Arrays, P. 280 (John Wiley and Sons, Mew York. Y.Y... 1974).

[2] Jordan, E. C., Electromagnetic Waves and Radiating Systems, p. 312 and p. 512 (Prentice-Ha 1 , Englewood Cliffs, N.J., 1950). 
MBS-114A (REV. $9-78$ )

\begin{tabular}{|c|c|c|c|}
\hline $\begin{array}{l}\text { U.S. DEPT. OF COMM. } \\
\text { BIBLIOGRAPHIC DATA } \\
\text { SHEET }\end{array}$ & $\begin{array}{l}\text { 1. PUBLICATION OR REPORT NO. } \\
\text { NBSIR } 79-1605\end{array}$ & 2. Gov't Accession No, & W \\
\hline \multirow{2}{*}{\multicolumn{3}{|c|}{$\begin{array}{l}\text { 4. TITLE AND SUBTITLE } \\
\text { A Theoretical Study of Unbalanced Ground } \\
\text { Effects on Receiving Dipoles }\end{array}$}} & $\begin{array}{l}\text { 5. Publication Date } \\
\text { May } 1979\end{array}$ \\
\hline & & & 6. Performing Organization Code \\
\hline \multicolumn{3}{|l|}{$\begin{array}{l}\text { 7. AUTHOR(S) } \\
\text { M. T. Ma }\end{array}$} & 8. Performing Organ. Report No. \\
\hline \multicolumn{3}{|c|}{ 9. PERFORMING ORGANIZATION NAME AND ADDRESS } & $\begin{array}{l}\text { 10. Project/Task/Hork Unit No. } \\
7233282\end{array}$ \\
\hline \multicolumn{3}{|c|}{$\begin{array}{l}\text { NATIONAL BUREAU OF STANDARDS } \\
\text { DEPARTMENT OF COMMERCE } \\
\text { WASHINGTON, DC } 20234\end{array}$} & 11. Contract/Grant No. \\
\hline \multirow{2}{*}{\multicolumn{3}{|c|}{ 12. SPONSORING ORGANIZATION NAME AND COMPLETE ADDRESS (Street, City, State, ZIP) }} & 13. Type of Report \& Period Covered \\
\hline & & & 14. Sponsoring Agency Code \\
\hline
\end{tabular}

15. SUPPLEMENTARY NOTES

Document describes a computer program; SF-185, FIPS Software Summary, is attached.

16. ABSTRACT (A 200-word or less factual summary of most significant information. If documert includes a significant bibliography or literature survey, mention it here.)

Balanced ground effects on the performance of some antenna systems are relatively well known and can be taken into account by the design engineer. Unbalanced ground effects on a measuring system are, however, more complicated and make a thorough understanding difficult. In this report, specific ground effects on the calibration of a dipole antenna with an arbitrary inclination angle with respect to the ground are analyzed by means of a theoretical model. Nlumerical results representing this undesired effect are also included.

17. KEY WORDS (six to twelve entries; alphabetical order; capitalize only the first letter of the first key word unless a proper nams; separated by semicolons)

Key Words: Dipole antenna; ground effect; unbalanced system.

18. AVAILABILITY X Unlimited

For Official Distribution. Do Wot Release to NTIS

Order From Sup. of Doc., U.S. Government Printing Office, Wasinington, DC 20402, SD Stock No. SNO03-003-

X Order From National Technical Information Service (NTIS), Springfield, VA. 22161

\begin{tabular}{|l|c|}
\hline $\begin{array}{l}\text { 19. SECURITY CLASS } \\
\text { (THIS REPORT) }\end{array}$ & $\begin{array}{c}\text { 21. NO. OF } \\
\text { PRINTED PAGES } \\
\text { UNCLASSIFIED }\end{array}$ \\
\hline $\begin{array}{l}\text { 20. SECURITY CLASS } \\
\text { (THIS PAGE) }\end{array}$ & 22. Price \\
UNCLASSIFIED & $\$ 3.50$ \\
\hline
\end{tabular}

USCOMM-DC 

